\title{
THYROID MALIGNANCY RISK OF INCIDENTAL THYROID NODULES IN PATIENTS WITH NON-THYROID CANCER
}

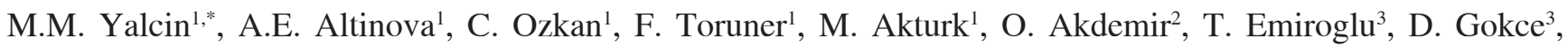 \\ A. Poyraz ${ }^{4}$, F. Taneri ${ }^{5}$, I. Yetkin ${ }^{1}$
Gazi University Faculty of Medicine, ${ }^{1}$ Department of Endocrinology and Metabolism, ${ }^{2}$ Department of Nuclear Medicine, ${ }^{3}$ Department of Internal Medicine, ${ }^{4}$ Department of Pathology, ${ }^{5}$ Department of General Surgery, Ankara, Turkey

\begin{abstract}
Context. Thyroid incidentaloma is a common disorder in endocrinology practice. Current literature regarding the risk of thyroid cancer in incidentalomas found in patients with non-thyroid cancer is limited.

Objective. The aim of the present study was to investigate the frequency of thyroid malignancy in thyroid incidentalomas detected in patients with non-thyroid cancer.

Design. Case control study.

Subjects and Methods. The database of 287 thyroid nodules from 161 patients with a history of nonthyroid cancer followed between 2008 and 2014 were retrospectively evaluated.

Results. From 287 thyroid nodules, $69.7 \%$ had a benign final cytology. Thyroid cancer detected in one nodule while follicular neoplasia detected in 4 nodules, atypia of unknown significance (AUS) detected in 10 nodules, Hurthle cell neoplasia detected in 5 nodules and suspicious for malignancy detected in 6 nodules according to fine needle aspiration biopsy results. Metastasis of the non-thyroid cancer to the thyroid gland was detected in 4 nodules. Twenty seven nodules from 15 patients were removed with surgery. There were 3 malignant nodules found after surgery (1 papillary, 1 follicular and 1 medullary cancer). In addition to these three thyroid cancers, two patients with benign nodules had co-incidental thyroid cancer detected after surgery. Finally, $11.1 \%$ of thyroid nodules which underwent thyroid surgery had malignant histopathology except for co-incidental and metastatic cancers.

Conclusions. The frequency of thyroid malignancy seems not to be substantially increased in incidental thyroid nodules detected in patients with non-thyroid cancer when these patients were evaluated in nodule-based approach.
\end{abstract}

Key words: thyroid cancer, non-thyroid cancer, thyroid nodules.

\section{INTRODUCTION}

Thyroid incidentaloma can be defined as an asymptomatic thyroid lesion detected during the radiological imaging methods including ultrasonography (US), computed tomography (CT), magnetic resonance imaging (MRI) and positron emission tomography (PET/ CT) for reasons unrelated to the thyroid gland (1). The frequency of thyroid nodules detected by USG ranges between $30-67 \%(2,3)$. So that, thyroid incidentalomas are frequently seen and to rule out the malignancy is the main problem (4). The rate of thyroid cancer has been reported as $12 \%$ in thyroid nodules incidentally found by US (5).

The increased frequency of secondary cancers has been observed in patients with thyroid cancer in observational studies (6-8). Also, a previous study from Turkey suggested that the occurrence of multiple primary tumors is common in patients with differentiated thyroid cancer (9). However, the literature associated with the risk of thyroid malignancy in patients with non-thyroid cancers is few $(7,10)$. All of these studies included heterogeneous groups with respect to cancer types of non-thyroid cancer. Also, study designs (nodule based, patient based) and end-points (cytology, histopathology) were different in the literature. So, interpretation of these studies leads to confusing results. Also, current data regarding the evaluation of the thyroid fine needle aspiration biopsy (FNAB) results in thyroid incidentalomas in patients with non-thyroid cancer with an endocrine perspective is limited.

In the present study, we aimed to investigate the frequency of thyroid malignancy based on the results of cytology and histopathology from thyroid nodules found incidentally in patients previously diagnosed with nonthyroid cancer retrospectively.

*Correspondence to: Mehmet Muhittin Yalcin, Gazi University Faculty of Medicine, Endocrinology and Metabolism, Ankara, 06500, Turkey, E-mail: yalcin.muhittin@gmail.com 


\section{MATERIAL AND METHODS}

FNABs of 287 thyroid nodules from 161 patients with a history of non-thyroid cancer were retrospectively evaluated. Ultrasonography guided FNABs (US-FNABs) were performed by experienced endocrinologists in our institution between January 2008 and February 2014. The study protocol was approved by the local ethic committee.

The maximal diameters of the nodules, cytology results of FNABs, and the types of primary tumors were recorded. FNAB results from all patients and histopathology results of the nodules which underwent thyroid surgery were recorded.

The indications for FNABs in the first visit and follow-up were size of the nodule (nodule maximal diameter $>10 \mathrm{~mm}$ ), or any suspicion of thyroid malignancy (rapid growth of the nodule), physical examination findings like fixed nodule or suspicious findings detected by ultrasonography (micro calcifications, central vascularity or irregular border). US-FNABs were performed under the guidance of continuous real time US with a 22-gauge needle attached to a $10-\mathrm{mL}$ disposable plastic syringe without local anesthesia. Each nodule was aspirated at least twice. Materials obtained from FNABs were

Table 1. The distribution of non-thyroid cancers

\begin{tabular}{lcc}
\hline & $\begin{array}{c}\mathrm{n}(\%) \\
\text { (nodule } \\
\text { distribution) }\end{array}$ & $\begin{array}{c}\mathrm{n}(\%) \\
\text { (patient } \\
\text { distribution) }\end{array}$ \\
\hline Breast Cancer & $94(32.8)$ & $53(32.9)$ \\
Hematologic Cancer & $79(27.5)$ & $41(25.5)$ \\
Gastrointestinal Cancer & $27(9.4)$ & $15(9.3)$ \\
Gynecologic Cancer & $18(6.3)$ & $10(6.2)$ \\
Lung Cancer & $17(5.9)$ & $12(7.5)$ \\
Genitourinary Cancer & $17(5.9)$ & $11(6.8)$ \\
Skin Cancer & $15(5.2)$ & $9(5.6)$ \\
Other & $20(7.0)$ & $10(6.2)$ \\
Total & $287(100)$ & $161(100)$ \\
\hline
\end{tabular}

immediately smeared on glass slides after aspiration and fixed by air-drying. Thyroid FNAB results were categorized according to Bethesda classification. In the context of insufficient results or atypia of unknown significance (AUS), repeated biopsies were performed. Final cytology was defined as the cytology result of the last biopsy performed for that nodule.

\section{RESULTS}

Of the 161 patients included in the study, 72.7 $\%$ of patients were female and mean age of the patients was $57.6 \pm 10.8$ years. Of the 287 nodules, mean of the maximal diameter of the nodules biopsied was 17.0 $\pm 9.6 \mathrm{~mm}$. The distribution of the non-thyroid cancers were listed in Table 1. Breast cancer was the most common primary malignancy.

There were 356 biopsy séances from 287 nodules. The reasons of repetitions were insufficient biopsy results, biopsies resulted as AUS or growth of the nodule. Final cytology results of nodules from non-thyroid cancer patients as well as according to non-thyroid cancer types were shown in Tables 2 and 3. From 287 thyroid nodules, $69.7 \%$ had a benign final cytology while $19.9 \%$ of the nodules had insufficient cytology despite repetitions. One

Table 2. Final cytology results of nodules from non-thyroid cancer patients

\begin{tabular}{lc}
\hline & $\mathrm{n}(\%)$ \\
\hline Benign & $200(69.7)$ \\
Follicular Neoplasia & $4(1.4)$ \\
AUS & $10(3.5)$ \\
Hurthle cell neoplasia & $5(1.7)$ \\
Suspicious for malignancy & $6(2.1)$ \\
Malignant & $1(0.3)$ \\
Metastasis & $4(1.4)$ \\
Insufficient & $57(19.9)$ \\
Total & $287(100)$ \\
\hline
\end{tabular}

Table 3. Final cytology results according to non-thyroid cancer types

\begin{tabular}{|c|c|c|c|c|c|c|c|c|}
\hline & $\begin{array}{l}\text { Breast } \\
\text { cancer }\end{array}$ & $\begin{array}{l}\text { Lung } \\
\text { cancer }\end{array}$ & $\begin{array}{c}\text { GU } \\
\text { cancer }\end{array}$ & $\begin{array}{l}\text { Gynecologic } \\
\text { cancer }\end{array}$ & $\begin{array}{c}\text { GIS } \\
\text { cancer }\end{array}$ & $\begin{array}{c}\text { Skin } \\
\text { cancer }\end{array}$ & $\begin{array}{l}\text { Hematologic } \\
\text { cancer }\end{array}$ & Other \\
\hline Benign & $76(80.9)$ & $10(58.8)$ & $11(64.7)$ & $11(61.1)$ & $16(59.3)$ & $10(66.7)$ & $54(68.4)$ & $12(60.0)$ \\
\hline Follicular neoplasm & $0(0)$ & $0(0.0)$ & $1(5.9)$ & 0 & 0 & 0 & $3(3.8)$ & 0 \\
\hline AUS & $3(3.2)$ & $1(5.9)$ & $1(5.9)$ & $1(5.6)$ & $3(11.1)$ & 0 & 0 & $1(5.0)$ \\
\hline Hurthle cell neoplasia & $1(1.1)$ & $0(0.0)$ & 0 & $1(5.6)$ & 0 & 0 & $2(2.5)$ & $1(5.0)$ \\
\hline Suspicious for cancer & $2(2.1)$ & $0(0.0)$ & 0 & 0 & 0 & 0 & $3(3.8)$ & $1(5.0)$ \\
\hline Malignant & $0(0)$ & $0(0.0)$ & $1(5.9)$ & 0 & 0 & 0 & 0 & 0 \\
\hline Metastasis & $0(0.0)$ & $2(11.8)$ & 0 & 0 & 0 & 0 & $2(2.5)$ & 0 \\
\hline Insufficient & $12(12.7)$ & $4(23.5)$ & $3(17.6)$ & $5(27.7)$ & $8(29.6)$ & $5(33.3)$ & $15(19.0)$ & $5(25.0)$ \\
\hline
\end{tabular}

Data were expressed as $n(\%)$, AUS, atypia of unknown significance; GU, genitourinary; GIS, gastrointestinal system. 
Table 4. Results of cytology and histopathology of nodules surgically removed

\begin{tabular}{lcccc}
\hline & \multicolumn{3}{c}{ Histopathological Results } \\
\cline { 2 - 5 } & Benign & Papillary cancer & Follicular cancer & Medullary cancer \\
\hline Benign Cytology & 13 & 0 & 0 & 0 \\
Follicular neoplasia & 1 & 0 & 0 & 0 \\
AUS & 2 & 0 & 1 & 0 \\
Suspicious Cytology & 4 & 0 & 0 & 0 \\
Hurthle cell Cytology & 1 & 0 & 0 & 0 \\
Malignant Cytology & 0 & 0 & 0 & 1 \\
Insufficient & 3 & 1 & 1 & 0 \\
Total & 24 & 1 & & 1 \\
\hline
\end{tabular}

nodule had a malignant cytology, 4 nodules follicular neoplasia, 10 nodules AUS, 5 nodules Hurthle cell neoplasia, 6 nodules suspicious for malignancy in FNABs. Metastasis of the non-thyroid cancer to the thyroid gland was detected in 4 nodules. Two of 4 had a history of lung cancer and the other two had a history of hematologic cancer. None of the patients with a metastatic cytology underwent thyroidectomy, all of them were treated with chemotherapy targeting the primary cancer.

As seen in Table 4, twenty seven nodules from 15 patients were removed with thyroid surgery. Seven nodules with a final cytology of AUS, one nodule with a final cytology of suspicious for papillary thyroid cancer and four nodules with a final cytology of Hurthle cell neoplasia could not be removed by surgery or re-biopsied because of patients' poor general health or unwillingness to thyroidectomy. There were 3 malignant nodules found after surgery (1 papillary, 1 follicular and 1 medullary cancer). One nodule with insufficient cytology was papillary cancer, one nodule with suspicious cytology was follicular cancer and one nodule with malignant cytology was medullary cancer in histopathology results. In addition to these three thyroid cancers, two patients with benign nodules had co-incidental thyroid cancer detected after surgery. After all, we found that $11.1 \%$ of thyroid nodules (3 of 27 nodules) had malignant pathology except coincidental thyroid cancer.

\section{DISCUSSION}

Endocrinologists frequently face with the evaluation of thyroid nodules in non-thyroid cancer patients as a result of aging of the population, increasing cancer rates and imaging modalities. Nevertheless, the frequency of thyroid cancer in incidentally found thyroid nodules in these patients is still not fully known. As far as we know, there are a limited number of studies on the prevalence of primary thyroid cancer in non-thyroid cancer patients in the literature (10-22).

In the present study, we showed that the frequency of thyroid malignancy in incidentally found thyroid nodules during the imaging studies performed for the investigation of non-thyroid cancer who underwent surgery was $11.1 \%$ when we exclude coincidental thyroid cancers and metastasis to the thyroid gland, although malignancy risk was even lower in the whole group (3 thyroid cancers detected in 267 nodules). According to our data, non-thyroid cancer patients may not have substantially increased risk for thyroid malignancy when nodule based approach was performed. In the study of Wilhelm et al. (11), the presence of a thyroid cancer in patients who have another primary malignancy and referred to a surgery clinic for incidental thyroid nodule was found as $24.3 \%$. But, they included co-incidental thyroid cancer and metastasis to thyroid in the ratio of thyroid malignancy. The difference between Wilhelm's study and ours was the ratio of patients who need surgery. Such that, 57\% of the referred patients had atypical biopsy results (not described in detail) warranting surgery in their study group whereas this ratio was lower in our study group. In the study of Cohen et al. (12), only 15 of 102 patients with thyroid incidentalomas detected on FDG-PET/CT were evaluated with FNAB, 7 of whom had a diagnosis of thyroid cancer according to FNAB results. As the number of patients who were histopathologically evaluated in their study group, it was hard to decide the thyroid cancer rates of the whole study group. This phenomenon can be attributed to most of the studies evaluating thyroid incidentalomas detected on FDGPET/CT. King et al. (23) reported that all of the 22 thyroid incidentalomas found on FDG-PET/CT were evaluated with FNAB and thyroid cancer (when coincidental thyroid cancers were excluded) was detected in $14 \%$ of the incidentalomas. Kim et al. (22) found that thyroid malignancy rate was $24.3 \%$ according to FNAB results in a large number of incidentalomas found on FDG-PET/CT. But, the histopathology results were 
not discussed in the article. The atypical thyroid FNAB results (Bethesda category IV and V) were reviewed in the study of Duskova et al. (15). Eleven of the 21 patients with a history of malignancy had metastasis of the initial malignancy whereas 8 of the 21 patients had thyroid cancer most of which was undifferentiated thyroid cancer. As a result, there are different ratios for thyroid malignancy risk in incidentalomas found in non-thyroid cancer patients in the literature. This difference may come from the departments where studies were conducted such as endocrinology, surgery or oncology; availability of FNABs, thyroid surgery and existence of metastasis or co-incidental thyroid cancer in the evaluation of thyroid malignancy risk in non-thyroid cancer patients. In our study, only 3 nodules of whole study group were diagnosed as thyroid malignancy. This result may be related to our selection of only high risk patients for thyroid surgery who had already have a primary cancer as well as unwillingness or unhealthiness of the patients to surgery. Therefore, the other reason of discordant results in terms of thyroid malignancy rates in the previous studies may be related to the selection criteria of the patient group or the determination of end-points. A selection bias in non-thyroid cancer patients in the literature may exist like in patients with autoimmune thyroiditis who have different thyroid cancer rates according to surgical or cytological series (24).

In our study, the distribution of FNAB cytology results from different non-thyroid cancers seems to be similar although breast cancer was the most frequent non-thyroid cancer type. The distribution of non-thyroid cancers was different in previous studies $(11,18,22,25,26)$. Indeed, the possible effects of the specific types of the non-thyroid cancer on the malignancy rates of thyroid incidentalomas is not known. In population-based epidemiological studies, the risk of subsequent thyroid cancer differed between various cancer types $(10,16)$. Lal et al. showed that there is increased subsequent thyroid cancer risk in almost all non-thyroid cancer types except bladder and uterus cancers (16). Also, subsequent thyroid cancer risk in patients with renal and breast cancers remained high for 10 years. Different previous studies had different spectrum of non-thyroid cancer types such as gynecologic cancers were predominant in the study of Gavriel et al. (25), gastrointestinal cancers in the study of Wilhelm et al. (11), head and neck cancers in the study of Nam et al. (27) and lung cancers in the study of Ishimori et al. (18). Some other studies did not mention the types of primary cancers $(12,28)$. On the other hand, Fanti et al. (26) selected thyroid incidentalomas from primary melanoma patients and they did not find any thyroid malignancy among 102 incidentally found thyroid nodules. Moreover, no significant effect of non-thyroid cancer type in the risk of thyroid cancer in thyroid incidentalomas detected on FDG-PET/CT was observed in the study of Kim et al. (22). Taken together, the idea that non-thyroid cancer type is an important factor for the risk of thyroid malignancy in incidentally found thyroid nodules needs further evaluation.

Incidental thyroid nodule is defined as the detection of a thyroid nodule with imaging studies performed for any reason which is unrelated with thyroid nodule. These nodules can be detected with US, CT, MRI or FDG-PET/CT. Recent publications mostly targeted the incidental thyroid nodules found with FDG-PET/CT performed for non-thyroid cancer $(12-14,21,22,28,29)$. However, we included thyroid incidentalomas detected with either of all imaging studies as Wilhelm et al. did in their study (11). The imaging technique using for staging primary cancer differs between cancer types and sometimes between activities of the cancer. Especially, FDG-PET/CT imaging is used in relatively aggressive cancers. So, including thyroid incidentalomas identified by only one imaging method cannot cover all the cancer types. This may partly explain the relatively high cancer rates detected from thyroid incidentalomas identified by FDG-PET/CT imaging and also low cancer rates found in our study as we included thyroid incidentalomas from all kinds of detection methods.

Co-incidentally found thyroid carcinoma out of the suspected nodule is not so rare. Therefore, malignancy rate should be defined according to the cancers found in the nodule which was investigated. Thus, it is reasonable to define the malignancy risk as nodule-based instead of patient-based especially in a study group with multiple nodules which we did in our study as the important feature of the present study. We think that future large-scale studies which consider nodule-based approach for the investigation of thyroid cancer risk in non-thyroid cancer patients are needed.

In our study, there are a relatively high number of patients with thyroid incidentalomas who could not be evaluated with further tests (re-biopsy, operation) because of poor health status. Therefore, the limitations of the present study were that the number of our patients who undergo thyroidectomy for the suspicion of thyroid cancer was small and the repetitions of the FNABs could not be done as expected especially in patients with primary cancer which is not in remission. 
Poor general health in some patients or unwillingness to thyroid operation were the reasons of a low number of thyroidectomies in these patients. However, these problems also apply to the previous studies which had a small number of patients for final diagnosis. The other limitation was the relatively higher rate of insufficient FNAB results. It may come from our approach that we performed FNAB even in smaller thyroid nodules. Nevertheless, our insufficient FNAB ratio is in accordance with the other groups reporting as 5-20\% (30).

In conclusion, our study is a large study group which is evaluating incidentalomas found in nonthyroid cancer patients all with FNAB and indicates that frequency of thyroid malignancy seems not to be substantially increased when these patients were evaluated in nodule-based approach. Future studies are needed to compare the thyroid malignancy risk in thyroid incidentalomas from non-thyroid cancer patients with the incidentalomas from healthy subjects.

\section{Conflict of interest}

The authors declare that they have no conflict of interest concerning this article.

\section{Acknowledgement}

The authors declare that there was no funding for this study.

\section{References}

1. Jin J, McHenry CR. Thyroid incidentaloma. Best Pract Res Clin Endocrinol Metab 2012; 26(1):83-96.

2. Ezzat S, Sarti DA, Cain DR, Braunstein GD. Thyroid incidentalomas. Prevalence by palpation and ultrasonography. Arch Intern Med 1994; 154(16):1838-1840.

3. Bartolotta TV, Midiri M, Runza G, Galia M, Taibbi A, Damiani L, Palermo Patera G, Lagalla R. Incidentally discovered thyroid nodules: incidence, and greyscale and colour Doppler pattern in an adult population screened by real-time compound spatial sonography. Radiol Med 2006; 111(7):989-998.

4. Vassiliadi DA, Tsagarakis S. Endocrine incidentalomas-challenges imposed by incidentally discovered lesions. Nat Rev Endocrinol 2011; 7(11):668-680.

5. Nam-Goong IS, Kim HY, Gong G, Lee HK, Hong SJ, Kim WB, Shong YK. Ultrasonography-guided fine-needle aspiration of thyroid incidentaloma: correlation with pathological findings. Clin Endocrinol (Oxf) 2004; 60(1):21-28.

6. Lu CH, Lee KD, Chen PT, Chen CC, Kuan FC, Huang CE, Chen MF, Chen MC. Second primary malignancies following thyroid cancer: a population-based study in Taiwan. Eur J Endocrinol 2013; 169(5):577-585.

7. Sandeep TC, Strachan MW, Reynolds RM, Brewster DH, Scelo G, Pukkala E, HHemminki K, Anderson A, Tracey E, Friis S, McBride ML, Kee-Seng C, Pompe-Kirn V, Kliewer EV,Tonita JM, Jonasson JG, Martos C, Boffetta P, Brennan P. Second primary cancers in thyroid cancer patients: a multinational record linkage study. J Clin Endocrinol Metab 2006; 91(5):1819-1825.
8. Kim C, Bi X, Pan D,Chen Y, Carling T, Ma S, Udelsman R, Zhang $\mathrm{Y}$. The risk of second cancers after diagnosis of primary thyroid cancer is elevated in thyroid microcarcinomas. Thyroid 2013; 23(5):575-582. 9. Omur O, Ozcan Z, Yazici B, Akgun A, Oral A, Ozkilic H. Multiple primary tumors in differentiated thyroid carcinoma and relationship to thyroid cancer outcome. Endocr J 2008; 55(2):365-372.

10. Ronckers CM, McCarron P, Ron E. Thyroid cancer and multiple primary tumors in the SEER cancer registries. Int J Cancer 2005; 117(2):281-288.

11. Wilhelm SM, Robinson AV, Krishnamurthi SS, Reynolds HL. Evaluation and management of incidental thyroid nodules in patients with another primary malignancy. Surgery 2007; 142(4):581-586.

12. Cohen MS, Arslan N, Dehdashti F, Doherty GM, Lairmore TC, Brunt LM, Moley JF. Risk of malignancy in thyroid incidentalomas identified by fluorodeoxyglucose-positron emission tomography. Surgery 2001; 130(6):941-946.

13. Nilsson IL, Arnberg F, Zedenius J, Sundin A. Thyroid incidentaloma detected by fluorodeoxyglucose positron emission tomography/computed tomography: practical management algorithm. World J Surg 2011; 35(12):2691-2697.

14. Bertagna F, Treglia G, Piccardo A, Giubbini R. Diagnostic and clinical significance of F-18-FDG-PET/CT thyroid incidentalomas. J Clin Endocrinol Metab 2012; 97(11):3866-3875.

15. Duskova J, Rosa P, Preucil P, Svobodova E, Lukas J. Secondary or second primary malignancy in the thyroid? metastatic tumors suggested clinically: a differential diagnostic task. Acta Cytol 2014; 58(3):262-268.

16. Lal G, Groff M, Howe JR, Weigel RJ, Sugg SL, Lynch CF. Risk of subsequent primary thyroid cancer after another malignancy: latency trends in a population-based study. Ann Surg Oncol 2012; 19(6):1887-1896.

17. Kang KW, Kim SK, Kang HS, Lee ES, Sim JS, Lee IG, Jeong SY, Kim SW. Prevalence and risk of cancer of focal thyroid incidentaloma identified by $18 \mathrm{~F}$-fluorodeoxyglucose positron emission tomography for metastasis evaluation and cancer screening in healthy subjects. J Clin Endocrinol Metab 2003; 88(9):4100-4104.

18. Ishimori T, Patel PV, Wahl RL. Detection of unexpected additional primary malignancies with PET/CT. J Nucl Med 2005; 46(5):752-757.

19. Are C, Hsu JF, Schoder H, Shah JP, Larson SM, Shaha AR. FDG-PET detected thyroid incidentalomas: need for further investigation? Ann Surg Oncol 2007; 14(1):239-247.

20. Bae JS, Chae BJ, Park WC, Kim JS, Kim SH, Jung SS, Song BJ. Incidental thyroid lesions detected by FDG-PET/CT: prevalence and risk of thyroid cancer. World J Surg Onco. 2009; 7:63.

21. Elzein S, Ahmed A, Lorenz E, Balasubramanian SP. Thyroid incidentalomas on PET imaging - Evaluation of management and clinical outcomes. Surgeon 2015; 13(2):116-120.

22. Kim H, Kim SJ, Kim IJ, Kim K. Thyroid incidentalomas on FDG $\mathrm{PET} / \mathrm{CT}$ in patients with non-thyroid cancer - a large retrospective monocentric study. Onkologie 2013; 36(5):260-264.

23. King DL, Stack BC, Jr., Spring PM, Walker R, Bodenner DL. Incidence of thyroid carcinoma in fluorodeoxyglucose positron emission tomography-positive thyroid incidentalomas. Otolaryngol Head Neck Surg 2007; 137(3):400-404.

24. Castagna MG, Belardini V, Memmo S, Maino F, Di Santo A, Toti P, Carli AF; Caruso G, Pacini F. Nodules in autoimmune thyroiditis are associated with increased risk of thyroid cancer in surgical series but not in cytological series: evidence for selection bias. J Clin Endocrinol Metab 2014; 99(9):3193-3198.

25. Gavriel H, Tang A, Eviatar E, Chan SW. Unfolding the role of PET FDG scan in the management of thyroid incidentaloma in cancer patients. Eur Arch Otorhinolaryngol 2015; 272(7):1763-1768. 26. Fanti PA, Dika E, Balestri R, Rech G, Bellavista S, Baldi E, Maibach HI, Patizi A. Evaluation of incidental thyroid nodules in patients with primary melanoma. G Ital Dermatol Venereol 2012; 147(1):91-97. 


\section{M.M. Yalcin et al.}

27. Nam SY, Roh JL, Kim JS, Lee JH, Choi SH, Kim SY. Focal uptake of (18)F-fluorodeoxyglucose by thyroid in patients with nonthyroidal head and neck cancers. Clin Endocrinol (Oxf) 2007; 67(1):135-139.

28. Marques P, Ratao P, Salgado L, Bugalho MJ. Thyroid Carcinoma Detected by 18F-Fluorodeoxyglucose Positron Emission Tomography Among Individuals Without Prior Evidence of Thyroid Disease: Relevance and Clinicopathological Features. Endocr Pract 2014; 20(11):1129-1136.
29. Bertagna F, Treglia G, Piccardo A, Giovannini E, Bosio G, Biasiotto G, Bahij el K, Maroldi R, Giubbini R. F18-FDG-PET/ CT thyroid incidentalomas: a wide retrospective analysis in three Italian centres on the significance of focal uptake and SUV value. Endocrine 2013; 43(3):678-685.

30. Alexander EK, Heering JP, Benson CB, Frates MC, Doubilet PM, Cibas ES, Marqusee E. Assessment of nondiagnostic ultrasound-guided fine needle aspirations of thyroid nodules. J Clin Endocrinol Metab 2002; 87(11):4924-4927. 